\title{
ЭКОЛОГИЧЕСКИЙ МЕНЕДЖМЕНТ В НЕФТЕГАЗОВЫХ КОМПАНИЯХ РОССИИ: РЕЙТИНГ ЭКОЛОГИЧЕСКОЙ ОТВЕТСТВЕННОСТИ
}

\author{
О. И. Горбунова, Л. В. Каницкая \\ Байкальский государственный университет, г. Иркутск, Российская Федерация
}

Информация о статье

Дата поступления

8 июня 2017 г.

Дата принятия к печати

29 июня 2017 г.

Дата онлайн-размещения 15 сентября 2017 г.

\section{Ключевые слова}

Экологический менеджмент; нефтегазовые компании; ISO 14001 ; система экологического менеджмента; рейтинг;

экологическая ответственность

\begin{abstract}
Аннотация
В статье оценивается нефтегазовый сектор России с точки зрения экологических аспектов. Эта отрасль имеет ключевое значение для национальной экономики и является одной из наиболее природоэксплуатирующих и «экологически грязных». Компании этого сектора характеризуются как наиболее «закрытые» и мало чувствительные к требованиям в области экологической ответственности и открытости информации. В работе приведены особенности методики формирования рейтинга экологической ответственности нефтегазовых компаний по разделу экологического менеджмента и представлены его результаты. Анализ сайта лидера рейтинга выявил отсутствие ряда важных сведений, касающихся управленческих аспектов. Отмечено, что рейтинг экологической ответственности является базой для создания качественного инструмента, позволяющего повысить открытость, прозрачность и заинтересованность нефтегазовых компаний в предупреждении и предотвращении негативных последствий их деятельности, а также в восстановлении нарушенной природной среды.
\end{abstract}

\section{ENVIRONMENTAL MANAGEMENT IN RUSSIAN OIL AND GAS COMPANIES: ENVIRONMENTAL RESPONSIBILITY RATING}

\section{Olga I. Gorbunova, Lyudmila V. Kanitskaya \\ Baikal State University, Irkutsk, Russian Federation}

\section{Article info}

Received

June 8, 2017

Accepted

June 29, 2017

Available online

September 15, 2017

\section{Keywords}

Environmental management; oil and gas company; ISO 14001; environmental management system; rating; environmental responsibility

\begin{abstract}
The article is devoted to the assessment of the situation in the Russian oil and gas sector from the point of view of the environmental aspects of the activities. This sector is of key importance for the national economy and is one of the most resource-intensive and environmentally "dirty". Companies in this sector are characterized as the most "closed" and insensitive to the demands of environmental responsibility and transparency. The article presents the methodical features and results of Russian environmental responsibility rating of oil \& gas companies in ecological management. The analysis of the website of the ranking leader revealed lack of some important information regarding the management aspects. The authors note that the rating of environmental responsibility is the basis for creating high-quality tool, which allows to increase the openness, transparency, the interest of oil companies in such type of activities as the management of the processes of prevention, prevent adverse impacts and restore disturbed natural environment.
\end{abstract}

\footnotetext{
Человеческая цивилизация начиная со второй половины XX в. столкнулась сглобальными экологическими вызовами, которые явились следствием реализации идей по достижению

высокого уровня техногенного развития и экономических завоеваний «общества потребления». Осознание проблем, связанных с надвигающейся экологической катастрофрой, 
привело к тому, что в последние десятилетия в большинстве стран мира отношение к экологическим аспектам при осуществлении производственной деятельности как к помехе для быстрого и эфффективного экономического развития окончательно исчезло.

Интеграция процессов, направленных на сохранение окружающей среды, ориентированная на партнерство между заинтересованными сторонами, была темой конференции ООН «Саммит Земли» в Рио-де-Жанейро еще в 1992 г. Один из принципов декларации, принятой на этой конференции, провозглашает, что при планировании экономического развития защита окружающей среды должна составлять неотъемлемую его часть и не может рассматриваться отдельно от него', поэтому экологический менеджмент относят к доминанте процессов развития производственной деятельности. Управленцы компаний и организаций во всем мире, их партнеры и акционеры все глубже осознают необходимость применения экологического менеджмента и реализации социально ответственного поведения [1;2].

Странам с развитой экономикой потребовалось почти 30 лет, чтобы связать экологическую политику с новым ключевым направлением глобального научно-технического прогресса - ресурсо- и энергосбережением, переходом к альтернативным источникам энергии и к «зеленой экономике», т. е. к подчинению экономического развития экологическому императиву. При реализации экологической политики многие государства и глобальные корпорации используют широкий арсенал средств как в правовой сфрере, так и при разработке новых экономических стимулов.

Следует особо обозначить существование в России специфического «видения» экологических проблем. В работе «Экономические аспекты экологической безопасности в нефтегазовой отрасли (международный опыт и российская практика)» [3] авторами анализируется ситуация, связанная с экологической проблематикой в России, показывается, что системный кризис 1990-х гг. негативно сказался на процессах постановки экологических проблем и попытках их разрешения. В частности, в исследовании констатируется, что в условиях спада производства, снижения его эффрективности, нарастания социальной нестабильности в стране внимание к охране окружающей среды и инвестиции в

1 Декларация Конференции Организации Объединенных Наций по проблемам окружающей человека среды. URL: http://www.un.org/ru/documents/decl_ conv/declarations/declarathenv.shtml. разработки в этой области свелись к минимуму, так как горизонт планирования резко сократился и приоритетным стало решение краткосрочных задач. Для законодательных и исполнительных структур власти экологические проблемы отошли на задний план, а роль экологических структур в правительстве России стала незначимой. Произошла своеобразная «деэкологизация» государственного управления: максимальное влияние на ситуацию Министерство охраны окружающей среды и природных ресурсов России оказывало в 1991-1996 гг., в 1996 г. оно было преобразовано в Комитет по охране окружающей среды с резким сокращением функций, а в 2000 г. Комитет был расформирован, а его функции переданы в Министерство природных ресурсов. При этом надо четко понимать, что главной задачей данного министерства является эксплуатация природных ресурсов. В условиях элементарного выживания резко снизилась приоритетность экологических проблем.

В настоящее время экономика России в результате утраты в 1990-е гг. наиболее высокотехнологичных производств характеризуется высокой природоемкостью. Такая ситуация сложилась в основных природоэксплуатирующих секторах, оказывающих существенное воздействие на экологическую ситуацию в России и мире: энергетическом, аграрном и лесном. В России затраты энергии, земли, леса и других ресурсов на единицу конечной продукции в среднем в 2-6 раз превышают затраты развитых стран. Очень велик разрыв в показателях природоемкости развитых стран и России [4].

Россия является вторым крупнейшим производителем природного газа и входит в тройку мировых лидеров производства жидких углеводородов, поэтому нефтегазовые компании активно вовлечены в международную торговлю углеводородным сырьем и его производных. При этом следует отметить, что российские компании экспортируют экологически чистую продукцию, а все экологические ущербы «оставляют» на своей территории. Поэтому исследование различных аспектов управления процессами воссоздания антропогенно-нарушенной среды обитания становится все более актуальным. Особенно это значимо для такого сектора экономики, как нефтегазовый, поскольку он обеспечивает экономическую, оборонную и национальную безопасность страны [5] и в то же время является одним из наиболее природоэксплуатирующих и «экологически грязных» секторов. 
До недавнего времени нефтегазовая отрасль характеризовалась как одна из наиболее «закрытых» и мало чувствительных к требованиям в области экологической ответственности и открытости информации. Однако создание эфффективной системы управления экологическими аспектами деятельности компаний и открытость «экологической» инфрормации являются основой обеспечения развития бизнеса в современных обществах [6].

Процессы разведки нефтяных и газовых месторождений, строительства скважин, эксплуатации месторождений, а также процессы нефтепереработки и нефтехимии сопровождаются различными побочными экологическими эффектами: механическим нарушением почвы, грунтов и напочвенного покрова, выбросами диоксида углерода в воздушное пространство при сжигании попутных газов, техногенными авариями, сопровождающимися пожарами, разливами нефти, загрязнением почвы и водного пространства и т. д. В последние годы экологические, а также социальные последствия деятельности нефтегазовых компаний, особенно на экологически уязвимых северных территориях, привлекают особое внимание.

С начала XXI в. к чиновникам, регулирующим природоохранные структуры, и владельцам нефтяного и газового бизнеса России также приходит понимание важности экологических проблем. В этой связи с целью повышения экологической безопасности нефтегазовых производств современные компании декларируют намерения разрабатывать и реализовывать научно-технические новшества в сорере экологического менеджмента, программы повышения энергоэфффективности и рационального использования ресурсов. Однако руководители различных уровней похоже оказались не готовы к той радикальной смене ориентиров в сорере управления процессами предупреждения и ликвидации негативных экологических последствий, которая происходит в мире повсеместно, и часто увязывают вопросы экологического менеджмента в основном с получением сертификата соответствия стандарту ISO 14001 [7].

Нефтегазовая промышленность с середины 1990-х гг. работает в направлении решения проблемы обеспечения охраны окружающей природной среды. Отдельные результаты уже достигнуты, но во многих крупных компаниях признают, что еще очень многое следует сделать при осуществлении геологоразведки, обустройстве месторождений, добыче, транспортировке и переработке углеводородного сырья, реали- зации продукции, выводе месторождений и мощностей из эксплуатации и рекультивации загрязненных территорий.

В разведке и добыче нефти и газа следует выделить главные принципы экологического управления на основе коллективного опыта, накопленного в нефтяной промышленности и при реализации программы ООН по окружающей среде ЮНЕП(United Nations Environment Programme, UNEP). Эти принципы должны помочь решить задачу полной интеграции охраны окружающей среды в нормативно-правовую деятельность и бизнес-процессы, касающиеся управления разведкой и добычей нефти и газа. Также они могут служить основой для разработки или совершенствования нормативно-правовых актов, политики и программ, направленных на минимизацию негативного воздействия нефтегазовой промышленности на окружающую среду.

Учитывая экспортную направленность деятельности российских компаний нефтегазового сектора, следует отметить, что большинство ведущих игроков мирового рынка нефти и газа должны соблюдать международные требования в сорере экологической безопасности и экологического менеджмента. Для того чтобы оставаться конкурентоспособными на мировом рынке, российские компании также вынуждены были внедрять системы экологического менеджмента на базе признанных во всем мире международных стандартов ISO 14000 при условии, что их применение носит исключительно добровольный характер. Поэтому на сегодняшний день практически все крупные компании нефтегазового сектора экономики России имеют в своей организационной среде сертифицированные системы экологического менеджмента.

Система экологического менеджмента (СЭМ) представляет собой часть общей системы менеджмента, используется для управления экологическими аспектами, а также выполнения принятых обязательств, учитывает риски и возможности компаний и организаций [8-10].

Оценить состояние экологического менеджмента в нефтегазовом секторе экономики можно по результатам российского экологического рейтинга нефтегазовых компаний. Пилотный проект по составлению данного рейтинга был осуществлен в 2014 г. по инициативе консультационно-аналитической группы в области топливно-энергетического комплекса «КРЕОН» и Всемирного фонда дикой природы (WWF) России при участии Национального рейтингового агентства [6; 11]. Целью данного проекта является получение объективной ин- 
формации об уровне воздействия участников рейтинга (компаний нефтегазового сектора) на окружающую природную среду. В 2016 г. рейтинг составлялся в третий раз.

Предполагается, что данный рейтинг должен способствовать снижению нагрузки на окружающую среду, повышению эффективности использования углеводородных ресурсов, а также ведению социально ответственного бизнеса в России. Одной из ключевых задач рейтинга является получение объективной информации об уровне воздействия отечественного нефтегазового сектора на окружающую среду².

Перечень компаний, включенных в рейтинг, определялся по показателю объема добычи нефти и природного газа. Его нижняя граница установлена на уровне 1,5 млн т. Таким образом, в выборку рейтинга за 2015 и 2016 г. попала 21 компания из нескольких сотен ${ }^{3}$.

Рейтинг нефтегазовых компаний проводят по трем разделам:

- экологический менеджмент;

- воздействие на окружающую среду;

- раскрытие информации [6].

В рамках первого раздела осуществляется оценка качества управления охраной окружающей среды в компаниях. Однако должны быть представлены аспекты, отражающие суть деятельности, называемой «экологический менеджмент».

При рейтинговой оценке данного раздела используются критерии, характеризующие наличие следующих элементов:

- количественные показатели результативности СЭМ;

- определенные требования и обязательства в экологической политике компании;

2 Рейтинг экологической ответственности нефтегазовых компаний России / WWF России ; CREON ; Нац. рейтинг. агентство. М., 2016. URL: wwf.ru>data/ greeneco/raitings2016.pdf.

${ }^{3}$ Нефтегазовый комплекс России: итоги 2015 года (по сост. на 8 мая 2016 г.) // Развитие электроэнергетики в России по итогам 2015 года : отраслев. отчет. URL: http://www.ranational.ru/sites/default/files / analitic_article/Neftegaz\%202015.pdf.
- политика по взаимодействию с коренными малочисленными народами Севера;

- программа по энергоэффективности;

- определенные компоненты в программах по сохранению биоразнообразия в регионах присутствия компании;

- компонент по спасению животных в Планах по предупреждению и ликвидации разливов нефти и нефтепродуктов (ПЛАРН);

- страхование экологических рисков на добровольной основе 4 .

Результаты рейтинга согласно представленной методике [6; 12] были рассчитаны с помощью качественной оценки: компаниям по каждому критерию был присвоен определенный цвет - красный, желтый, зеленый. Затем в рамках разделов рейтинга цветовой уровень переводился в баллы. Красному цвету присвоено значение 0 баллов, желтому 1 балл, зеленому - 2 балла. Для компаний рассчитывалось среднеарифметическое значение по каждому разделу (экологический менеджмент, воздействие на окружающую среду и прозрачность). Окончательные показатели рейтинга варьировались от 0 до 2 . Таким образом, были определены лидеры в каждом из трех разделов. Подведение итогов осуществлялось методом расчета средней оценки из трех значений с учетом предыдущего этапа для каждой компании.

Е. А. Шварц и другие констатировали, что при оценке компаний по разделу экологического менеджмента трудностей практически не возникало, так как все компании из рейтингового списка имели на своих официальных сайтах сведения о наличии сертификатов соответствия международному стандарту ISO 14001, текст экологической политики или аналогичный документ [6, с. 59].

Лидером рейтинга экологической ответственности за 2016 г. стала компания «Сахалин Энерджи», исходя из набранной суммы баллов $(1,86)$, эта компания должна быть лидером во всех трех разделах (табл.).

${ }^{4}$ URL: wwf.ru>data/greeneco/raitings2016.pdf.

Результаты рейтинга экологической ответственности компаний нефтегазового сектора России за 2016 г.

\begin{tabular}{|c|c|c|c|c|}
\hline Компания & $\begin{array}{c}\text { Итоговый балл } \\
\text { рейтинга }\end{array}$ & $\begin{array}{c}\text { Изменение балла } \\
\text { по сравнению } \\
\text { с } 2015 \text { г. }\end{array}$ & $\begin{array}{c}\text { Место по } \\
\text { итогам рейтинга } \\
2015 \text { г. }\end{array}$ & $\begin{array}{c}\text { Итоговое место } \\
\text { в рейтинге } \\
2016 \text { г. }\end{array}$ \\
\hline Сахалин Энерджи (Сахалин-2) & 1,8593 & $+0,3371$ & 3 & 1 \\
\hline Газпром & 1,7201 & $+0,1814$ & 2 & 2 \\
\hline Сургутнефтегаз & 1,6830 & $+0,1005$ & 1 & 3 \\
\hline Лукойл & 1,6527 & $+0,2790$ & 5 & 4 \\
\hline Салым Петролеум Девелопмент Н. В. & 1,6376 & $+0,2932$ & 7 & 5 \\
\hline Эксон Нефтегаз Лимитед (Сахалин-1) & 1,6302 & $+0,5672$ & 9 & 6 \\
\hline
\end{tabular}




\begin{tabular}{|l|r|r|r|r|}
\hline \multicolumn{1}{|c|}{ Компания } & $\begin{array}{c}\text { Итоговый балл } \\
\text { рейтинга }\end{array}$ & $\begin{array}{c}\text { Изменение балла } \\
\text { по сравнению } \\
\text { с 2015 г. }\end{array}$ & $\begin{array}{c}\text { Место по } \\
\text { итогам рейтинга } \\
2015 \text { г. }\end{array}$ & $\begin{array}{c}\text { Итоговое место } \\
\text { в рейтинге } \\
2016 \text { г. }\end{array}$ \\
\hline Новатэк & 1,4063 & $+0,4396$ & 12 & 7 \\
\hline Газпром нефть & 1,3795 & $+0,3593$ & 10 & 8 \\
\hline Роснефть & 1,3555 & $-0,0014$ & 6 & 9 \\
\hline Зарубежнефть & 1,2397 & $-0,1825$ & 4 & 10 \\
\hline
\end{tabular}

При анализе официальных данных на сайте лидера рейтинга ${ }^{5}$ с позиции управленческой деятельности и продекларированной открытости информации хотелось бы обнаружить следующие сведения:

1. Сертификат соответствия системы экологического менеджмента компании требованиям международного стандарта ISO 14001 (хотя не возникает сомнений, что этот сертифрикат у компании есть).

2. Раздел "Экологический менеджмент», который должен содержать описание процессов системы экологического менеджмента. На сайте в разделе «Безопасность и экология» имеются подразделы «Охрана труда», «Производственная безопасность» и «Безопасность дорожного движения», но нет информации, связанной с экологическим управлением. К вопросам экологии относится только небольшой фррагмент текста: «"Сахалин Энерджи" обеспечивает также экологическую безопасность и работает над сохранением биоразнообразия о. Сахалин. Инструментами этой деятельности являются, среди прочего, экологический контроль и мониторинг».

${ }^{5}$ Сахалин Энерджи : офиц. сайт компании. URL: http://www.sakhalinenergy.ru/ru/index.wbp.
3. Методы оценки количественных показателей СЭМ.

4. Информацию, касающуюся экологической политики компании, поскольку представлена «Политика устойчивого развития», в которой экологические принципы затрагивают главным образом природоохранную деятельность, но не аспекты собственно управленческой деятельности по воссозданию антропогенно нарушенной среды обитания.

В заключение следует отметить, что рейтинг экологической ответственности является базой для создания качественного инструмента, позволяющего повысить открытость, прозрачность и заинтересованность нефтегазовых компаний в управлении процессами предупреждения, предотвращения негативных последствий их деятельности, а также восстановления нарушенной природной среды. Кроме того, этот инструмент позволит наработать опыт в сорере экологического менеджмента и будет способствовать изменению сознания руководителей и управленцев нефтегазовых компаний в отношении экологических аспектов их деятельности.

\section{СПИСОК ИСПОЛЬЗОВАННОЙ ЛИТЕРАТУРЫ}

1. Горбунова О. И. Роль системы экологического менеджмента в интегрированной системе менеджмента компаний / О. И. Горбунова, М. В. Сенченко // Вестник Иркутского государственного технического университета. - 2010. - № 5 (45). - С. 286-290.

2. Shvarts E. Voluntary environmental standards in key Russian industries: a comparative analysis / E. Shvarts, J. Bunina, A. Knizhnikov // International Journal of Sustainable Development and Planning. — 2015. - Vol. 10, № 3. - P. 1-15. - DOI: 10.2495/SDP-V10-N3-331-346.

3. Никитина Ю. А. Экономические аспекты экологической безопасности в нефтегазовой отрасли (международный опыт и российская практика) : автореф. дис. ... канд. экон. наук : 08.00.14 / Ю. А. Никитина. - M., 2012. - 30 c.

4. Бобылев С. Н. Экономика природопользования : учебник / С. Н. Бобылев, А. Ш. Ходжаев. - М. : Издво МГУ, 2003. - 567 с.

5. Богомолова Е. Ю. Оценка влияния нефтегазового комплекса на ВВП России / Е. Ю. Богомолова, В. А. Хамнаев / / Современные проблемы и тенденции развития экономики и управления : материалы Междунар. науч.-практ. конфр., Екатеринбург, 10 мая 2016 г. : в 3 ч. — Уфра : Аэтерна, 2016. - Ч. 1. — С. 131-137.

6. Оценка экологической ответственности нефтегазовых компаний, действующих в России: рейтинговый подход / Е. А. Шварц, А. Ю. Книжников, А. М. Пахалов, М. Ю. Шерешева // Вестник Московского университета. Сер. 6, Экономика. - 2015. - № 5. - С. 46-67.

7. Горбунова О. И. Международные стандарты ISO 14000: факторы, препятствующие их реализации в России / О. И. Горбунова, Л.В.Каницкая / / Фундаментальные исследования. — 2016. — № 7-1. - С. 87-91.

8. Брюхова Е. С. Как сделать СЭМ результативной / Е. С. Брюхова / / Стандарты и качество. - 2017. № 5. - C. 32-33.

9. Пахомова Н. В. Новые инструменты экологического менеджмента в стандарте ISO 14001:2015 как фактор устойчивого развития нефтегазовых предприятий России / Н. В. Пахомова, А. В. Хорошавин // Нефртяное хозяйство. — 2016. — № 9. - С. 124-128. 
10. Ратнер С. В. Сравнительная эфффективность систем экологического менеджмента ИСО 14001 и EMAS: обзор исследований / С. В. Ратнер, Н. А. Алмастян / / Экономический анализ: теория и практика. - 2016. № 7 (454). - C. 106-118.

11. Шварц Е. А. Рейтинг экологической ответственности нефтегазовых компаний, действующих в России / Е. А. Шварц, А. М. Пахалов, А. Ю. Книжников / / Использование и охрана природных ресурсов в России. 2015. - № 1 (140). - С. 49-53.

12. Динамика рейтинга экологической ответственности нефртегазовых компаний, действующих в России, по данным за 2013-2014 годы / Е. А. Шварц, А. Ю. Книжников, А. М. Пахалов, Н. К. Кильзие / / Использование и охрана природных ресурсов в России. - 2015. - № 6 (144). - С. 7-16.

\section{REFERENCES}

1. Gorbunova O. I., Senchenko M. V. Role of the system of environmental management in the integrated system of company management. Vestnik Irkutskogo gosudarstvennogo tekhnicheskogo universiteta = Bulletin of Irkutsk State Technical University, 2010, no. 5 (45), pp. 286-290. (In Russian).

2. Shvarts E., Bunina J., Knizhnikov A. Voluntary environmental standards in key Russian industries: a comparative analysis. International Journal of Sustainable Development and Planning, 2015, vol. 10, no. 3, pp. 16.

3. Nikitina Yu. A. Ekonomicheskie aspekty ekologicheskoi bezopasnosti v neftegazovoi otrasli (mezhdunarodnyi opyt i rossiiskaya praktika). Avtoref. Kand. Diss. [Economic Aspects of Ecological Safety in Oil and Gas Industry (International and Russian Experience). Cand. Diss. Thesis]. Moscow, 2012. 30 p.

4. Bobylev S. N., Khodzhaev A. Sh. Ekonomika prirodopol'zovaniya [Environmental Economics]. Lomonosov Moscow State University Publ., 2003. 567 p.

5. Bogomolova E. Yu., Khamnaev V. A. Assessment of Influence of Oil and Gas Industry On Russian GDP. Sovremennye problemy i tendentsii razvitiya ekonomiki i upravleniya. Materialy Mezhdunarodnoi nauchno-prakticheskoi konferentsii. Yekaterinburg, 10 maya 2016 g. [Contemporary Problems and Development Trends in Economics and Management. Materials of International Research Conference. Yekaterinburg, May10, 2016]. Ufa, Aeterna Publ., 2016, pt. 1, pp. 131-137. (In Russian).

6. Shvarts E. A., Knizhnikov A. Yu., Pakhalov A. M., Sheresheva M. Yu. The assessment of environmental responsibility of oil and gas companies operating in Russia: the rating approach. Vestnik Moskovskogo universiteta. Seriya 6, Ekonomika = Moscow University Economics Bulletin, Series 6, Economy, 2015, no. 3, pp. 26-40. (In Russian).

7. Bogomolova E. Yu., Khamnaev V. A. International standards ISO 14000: factors impeding their implementation in Russia. Fundamental' nye issledovaniya = Fundamental Investigations, 2016, no. 7-1, pp. 87-91. (In Russian).

8. Bryukhova E. S. How to Make Environmental Management System Efficient. Standarty $i$ kachestvo = Standards and Quality, 2017, no. 5, pp. 32-33. (In Russian).

9. Pakhomova N. V., Khoroshavin A. V. New environmental management tools of ISO 14001:2015 as a factor of oil and gas Russian enterprises sustainable development. Neftyanoe khozyaistvo= Oil Industry, 2016, no. 9, pp. 124128. (In Russian).

10. Ratner S. V., Almastyan N. A. Comparing the efficiency of ISO 14001 and EMAS environmental management systems: a literature review. Ekonomicheskii analiz: teoriya i praktika = Economic Analysis: Theory and Practice, 2016, no. 7 (454), pp. 106-118. (In Russian).

11. Shvarts E. A., Pakhalov A. M., Knizhnikov A. Yu. Rating of environmental responsibility of oil and gas companies, operating in Russia. Ispolzovanie $i$ okhrana prirodnykh resursov $v$ Rossii $=$ Natural Resources Utilization and Conservancy in Russia, 2015, no. 1 (140), pp. 49-53. (In Russian).

12. Shvarts E. A., Knizhnikov A. Yu., Pakhalov A. M., Kil'zie N. K. Dynamics of environmental responsibility rating of oil and gas companies, operating in Russia, in 2013-2014. Ispolzovanie $i$ okhrana prirodnykh resursov $v$ Rossii $=$ Natural Resources Utilization and Conservancy in Russia, 2015, no. 6 (144), pp. 7-16. (In Russian).

\section{Информация об авторах}

Горбунова Ольга Ивановна - кандидат технических наук, доцент кафедры экономики и управления бизнесом, Байкальский государственный университет, 664003, г. Иркутск, ул. Ленина, 11, e-mail: olgavaliko@mail.ru.

Каницкая Людмила Васильевна - доктор химических наук, профессор кафедры экономики и управления бизнесом, Байкальский государственный университет, 664003, г. Иркутск, ул. Ленина, 11, e-mail:kanlv@mail.ru.

\section{Для цитирования}

Горбунова О.И. Экологический менеджмент в нефтегазовых компаниях России: рейтинг экологической ответственности / О.И. Горбунова, Л. В. Каницкая / / Известия Байкальского государственного университета. - 2017. - Т. 27, № 3. - С. 366371. - DOI: 10.17150/2500-2759.2017.27(3).366-371.

\section{Authors}

Olga I. Gorbunova - PhD in Engineering, Associate Professor, Department of Economics and Business Management, Baikal State University, 11 Lenin St., 664003, Irkutsk, Russian Federation, e-mail: olgavaliko@mail.ru.

Lyudmila V. Kanitskaya - DSc in Chemistry, Professor, Department of Economics and Business Administration, Baikal State University, 11 Lenin St., 664003, Irkutsk, Russian Federation, e-mail: kanlv@ mail.ru.

\section{For Citation}

Gorbunova O. I., Kanitskaya L. V. Environmental Management in Russian Oil and Gas Companies: Environmental Responsibility Rating. Izvestiya Baykal'skogo gosudarstvennogo universiteta = Bulletin of Baikal State University, 2017, vol. 27, no. 3, pp. 366371. DOI: 10.17150/2500-2759.2017.27(3).366-371. (In Russian). 